\title{
The Impact of Supply Chain Collaboration in Logistic Service for Small Medium Enterprise in East Java, Indonesia
}

\section{Sesilya Kempa, Novia Chandra Tanuwijaya, and Zeplin Jiwa Husada Tarigan}

Management Department, Petra Christian University, Jl. Siwalankerto 121-131, Surabaya 60236, Indonesia

\section{Abstract}

Fierce competition in the manufacturing field leads many manufacturing companies to shift their way of work. This shift was done by implementing supply chain management practices. The companies collaborate by implementing supply chain collaboration, including collaboration between Small Medium Enterprise (SMEs) and Third Party Logistic (3PL) where both parties share the benefits and risks. This study aims to examine the impact of supply chain collaboration on customer satisfaction through logistic services. The data were collected from SMEs engaged as 3PL partners in

Corresponding Author:

Sesilya Kempa

sesilya.kempa@petra.ac.id

Received: 16 February 2020 Accepted: 5 March 2020

Published: 10 March 2020

Publishing services provided by Knowledge

(c) Sesilya Kempa et al. This article is distributed under the terms of the Creative Commons Attribution License, which permits unrestricted use and redistribution provided that the original author and source are credited.

Selection and Peer-review unde the responsibility of the ICLBI (2018) Conference Committee.

\section{G OPEN ACCESS} the East Java region with a total of 75 SMEs. The questionnaires were distributed on 60 SMEs in which further proceeded by 42 SMEs with a response rate of $70 \%$ PLS (Partial Least Square) was used to process the data with the following results: i) supply chain collaboration influenced service quality relational logistics at 0.790 ; ii) supply chain collaboration did not have a significant impact on operational logistics service quality; Third, relational logistics service quality had a significant impact on operational logistics service quality at 0.466 and customer satisfaction at 0.197 ; Fourth, operational logistics service quality had an impact of 0.600 on customer satisfaction.

Keywords: Customer satisfaction factor; operational logistic service quality; relational logistic service quality; third party logistic.

\section{Introduction}

Today's business environment is very competitive. Thus, many companies look for opportunities outside the organization to collaborate with partners to ensure that their supply chain is efficient and responsive to dynamic market needs. Many companies are aware that this collaboration is needed with the aim of achieving mutual benefits greater than what the company will achieve individually [1]. In a series of processes from end to end in the supply chain, it is very possible to establish a form of collaboration.

A commonly carried out collaboration is a collaboration between companies and companies that provide logistical support service known as Third Party Logistic (3PL). 
This collaboration aims to enable companies to focus on the main industries they work on. Collaboration with logistic service providers makes the company service users feel calm about the risk of failure of logistics transactions because they have been handled by a service provider company. This kind of collaboration can also reduce substantial investment costs for logic related matters in order to increase the main business development capital. In addition, collaboration can increase the flexibility to reach markets where companies will be free to develop their markets and to realize economies of scale [2]. Based on the findings in the study conducted by Georgia Tech, good collaboration with $3 \mathrm{PL}$ will make the company able to reduce $15 \%$ of logistics costs, fixed asset investment in logistic by $25 \%$ and inventory costs by $11 \%$ [2].

Charvet et al. [4] revealed that logistics service quality has a significant relationship with company performance where service quality logistics can be a source of competitive advantage. Supply chain collaboration (SCC) will affect relational quality in the context of the logistics service industry [5]. Efficient relationship logistics is influenced by joint decision making and information sharing between the supply chain [6]. On the other hand, collaboration shows significant positive relationships with the level of timebased logistical service quality (timeliness) [7]. In order to achieve operational logistic effects, supply chain collaboration is needed [8]. The level of logistics services provided by the company then determines customer satisfaction [9].

Supply chain collaboration with 3PL has been carried out by many Small and Medium Enterprises (SMEs). Chain collaboration supply enables SMEs to work together and compete in the market to attract customer attention and market share at the same time. Wagner et al. [10] found something unique in SMEs that SMEs tend to have strong ties with partners in an informal form. SMEs that have inter-partnership relationships with other actors in the supply chain have a significant growth rate compared to those who do not [11]. However, basically, SMEs are still considered limited in several things related to the implementation of its supply chain management namely inefficient inventory management (39\%), lack of attention to uncertainty (30\%), valuing improper inventory costs (26\%), lack of communication and inaccurate data [12]. Further, one of the keys to the success of SMEs is to build information sharing with suppliers and build logistics capabilities [13--15].

\section{Literature Review and Hypothesis}




\subsection{Supply Chain Collaboration}

Supply chain collaboration is often defined as a form of collaboration carried out by two or more supply chain members in terms of sharing information, making shared decisions, and sharing benefits to satisfy the needs of end customers which then impacts profitability that can be enjoyed together [16]. Supply chain collaboration can only be understood as a decision-making process between interdependent parties at many levels of the supply chain that involves shared ownership decisions and collective responsibility for beneficial outcomes [17]. Supply chain collaboration can be measured by indicators of information sharing, decision synchronization, and incentive alignment [18].

\subsection{Logistic Service Quality}

Logistic service quality is an instrument used for measuring the perception of suppliers to value created for them by logistics services [19]. Logistics service quality is defined as a collection of performance factors and is measured by the ability to distribute products according to customer requirements [20]. Logistic service itself is divided into operational logistics service quality and relational logistics service quality.

Operational logistics service quality (OLSQ) is the perception of logistical activities carried out by service providers that contribute to the quality, productivity, and consistent efficiency [21]. In addition, operational service quality logistics is defined as the business operational delivery activities including physical features of services and perceived reliability, for example, to perform the promised services reliably and accurately [22]. Operational logistics service quality is information quality, timeliness, accuracy, error processing convenience, and reliability [23].

Relational Logistics Service Quality (RLSQ) is defined as a perception of logical activities that bring the company closer to its customers where the company will try to understand the needs and expectations of customers and develop a process for its customers [21]. The indicator of relational logistics service quality is focused on perceptions such as assurance, responsiveness, and caring [22].

\subsection{Customer Satisfaction}

Customer Satisfaction (CS) is a customers' state of mind about the company when their expectations on the product or service are met or exceeded [24]. Achievement of 
customer satisfaction is implemented can lead to corporate loyalty and repurchase [24]. Satisfied customers are good sources of increasing profitability. This is because satisfied consumers tend to be committed to better service and social organization services with service providers. On the contrary, dissatisfied companies complain more and rescue to buy back [25]. According to Williams et al. [25], customer satisfaction indicators can be measured in terms of structural quality, process quality, and outcome quality.

\section{Research Method}

This study was a causality study focused on finding explanations in the form of a causal relationship between several variables developed in management. The population in this study was 75 SME logistic service users. The sampling technique used was purposive sampling based on criteria set ahead namely samples taken based on the availability of information. Based on these criteria, the number of samples collected was 42 SMEs spread across Surabaya, Jember, Kediri, Madiun, Malang, Mojokerto, and Tulung Agung, East Java, Indonesia. Furthermore, this study used a relationship model to test existing hypotheses and used the Partial Least Square (PLS) technique to analyze the data.

\section{Findings and Discussion}

In this study, data analysis included evaluating the outer and inner model. The results of the data analysis show that all measurement indicators of research variables consist of supply chain collaboration, operational logistic service quality, relational logistic service quality, and customer satisfaction were valid. This is indicated by the coefficient of outer loading and cross-loading which ranges from 0.709 to 0.928 . It can be seen from the Cronbach Alpha coefficient showing values equal to 0.895 to 0.9951 while composite reliability shows a value equal to 0.935 to 0.957 . Based on the results of this analysis, indicators and research variables can be considered as valid and reliable. Coefficients (R2) are presented in Table 1.

TABLE 1: R-Square

Variable
Customer Satisfaction (Y)
Operational LSQ (Z1)
Relational LSQ (Z2)

\begin{tabular}{|c|c|}
\hline R Square \\
\hline 0.582 \\
\hline 0.659 \\
\hline 0.624 \\
\hline
\end{tabular}


Based on Table 1, it can be explained that the coefficient of OLSQ and RLSQ determination on customer satisfaction was 0.852 . This illustrates that $58.2 \%$ of customer satisfaction was influenced by OLSQ and RLSQ while the rest were other factors outside the research element. Meanwhile, OLSQ and RLSQ were influenced by supply chain collaboration by $65.9 \%$ and $62.4 \%$, the rest (34.1\% and $37.6 \%$ ) were other factors outside this study. Furthermore, the results of calculating the Q-Square value are as follows: 0.878 4. It shows that the diversity of the research data explained by the research model was $97.84 \%$ while the remaining (12.16\%) was explained by other factors outside the model. This research model can be considered to be good or relevant because it had good goodness of fit.

Table 2 presents the results of the hypothesis test that the effect of supply chain collaboration on the relational logistics service quality was indicated by $p$-values 0.000 $>0.05$. This means that supply chain collaboration had a significant impact on the relational logistics service quality. The 3PL company in East Java was able to synchronize data between relevant departments within the company as well as between SMEs and 3PL as the providers. In addition to the company's ability in synchronizing the data, it turns out that SMEs and 3PL were also able to share information to support customer satisfaction. This finding supports previous as in $[5,6]$.

TABLE 2: Hypothesis Test

\begin{tabular}{|c|c|c|c|c|c|}
\hline & $\begin{array}{l}\text { Original } \\
\text { Sample }\end{array}$ & $\begin{array}{c}\text { Sample } \\
\text { Mean (M) }\end{array}$ & $\begin{array}{l}\text { Standard } \\
\text { Deviation } \\
\text { (STDEV) }\end{array}$ & t Statistics & $P$ Values \\
\hline $\operatorname{SCC}\left(X_{1}\right)->\operatorname{RLSQ}\left(Z_{2}\right)$ & 0.790 & 0.801 & 0.054 & 14.685 & 0.000 \\
\hline $\operatorname{RLSQ}\left(Z_{2}\right)->\operatorname{CS}(Y)$ & 0.197 & 0.199 & 0.194 & 1.014 & 0.311 \\
\hline $\operatorname{SCC}\left(X_{1}\right)->\operatorname{OLSQ}\left(Z_{1}\right)$ & 0.391 & 0.410 & 0.243 & 1.610 & 0.107 \\
\hline $\operatorname{OLSQ}\left(Z_{1}\right)->\operatorname{CS}(Y)$ & 0.600 & 0.598 & 0.180 & 3.328 & 0.001 \\
\hline $\operatorname{RLSQ}\left(Z_{2}\right)->\operatorname{OLSQ}\left(Z_{1}\right)$ & 0.466 & 0.451 & 0.234 & 1.993 & 0.046 \\
\hline SCC (X1) -> OLSQ (Z1) -> CS (Y) & 0.235 & 0.234 & 0.152 & 1.545 & 0.122 \\
\hline $\operatorname{SCC}(\mathrm{X} 1)->\mathrm{RLSQ}(\mathrm{Z} 2)->\mathrm{OLSQ}(\mathrm{Z} 1)->\mathrm{CS}(\mathrm{Y})$ & 0.221 & 0.224 & 0.156 & 1.419 & 0.156 \\
\hline $\operatorname{SCC}(\mathrm{X} 1)->\mathrm{RLSQ}(\mathrm{Z} 2)->\mathrm{CS}(\mathrm{Y})$ & 0.156 & 0.159 & 0.153 & 1.016 & 0.310 \\
\hline SCC (X1) -> RLSQ (Z2) -> OLSQ (Z1) & 0.369 & 0.359 & 0.186 & 1.976 & 0.048 \\
\hline
\end{tabular}

Second, the results of the supply chain collaboration effect on logistics operation service quality above indicate that it is rejected. The effect of supply chain collaboration on logistics operations service quality is shown by $p$-values $0.107>0.05$. This shows that supply chain collaboration was not able to influence the operational logistics service quality due to information sharing between SMEs and $3 P L$ which was not 
on time. In this case, sometimes SMEs have to coordinate with the $3 \mathrm{PL}$ company by phone. This condition also occurs due to the existence of inaccurate information or data, especially the barcode data available to companies that cannot be read by the information technology system used by a 3PL company that required manual entry.

Third, the test results of the relational logistics service quality effect on service quality operational logistics show that it is accepted. This means that the higher relational logistics service quality, the more significant improvement made by the operational logistics service quality by 3PL in East Java. The results of the study show that there were delays in logistical services for several times. However, since the 3PL was doing a responsive service to the SMEs and caring about the inconsistencies in the data, the relationship between the two has a positive and significant impact. The existing error processing can be overcome by the 3PL by providing excellent service.

Fourth, the influence of relational logistics service quality on customer satisfaction is indicated by $p$-values $0.311>0.05$. This means that relational logistics service quality built did not affect customer satisfaction. Based on the results above, it is found that assurance, responsiveness, and caring were not able to satisfy the customers. Those need to be provided for SMEs by the 3PL especially on the assurance provided. Actually, the $3 \mathrm{PL}$ has provided responsiveness and caring. However, there is a need for policies to be taken by 3PL as a provider to provide assurance of damaged products and products that are late in delivery. In addition, 3PL has to provide certainty for customers to make claims for 3PL.

Fifth, the test results of the effect of operational logistic service quality on customer satisfaction are indicated by $0.001>0.05 p$-values. This means that operational logistics service quality chose a significant impact on customer satisfaction. The results of operational logistic services quality with information quality, timeliness, accuracy, convenience error processing, and reliability as the indicators have an impact on customer satisfaction. Operational ability of 3PL in maintaining products in order not to get error processing and its ability to ensure service reliability will enable SMEs to provide qualified products.

The first indirect impact was the effect of supply chain collaboration on customer satisfaction through operational logistics service quality which was indicated by $0.122>$ $0.05 p$-values. This means that supply chain collaboration cannot mediate the effect of supply chain collaboration on customer satisfaction through operational logistics service quality. The effect of supply chain collaboration on customer satisfaction through the operational logistics service quality of 0.235 was not significant. The ability of 3PL and SMEs to synchronize data and share information did not have any impact on 
improving product service quality through responsiveness and caring for the customers. This condition is the same as indirect effect supply chain collaboration on customer satisfaction through relational logistics service quality and operational logistics service quality was at 1.419. This result indicates that relational logistics service quality and operational logistics service quality cannot mediate the influence of collections on customer satisfaction.

Indirect effect supply chain collaboration on customer satisfaction through relational logistics service quality was 1.016 . This indicates that relational logistics service quality cannot mediate the influence of collections on customer satisfaction. Relational logistics service quality was able to facilitate the influence of the supply chain collaboration on service quality operational logistics. The higher supply chain collaborator between 3PL and SMEs will increase the relational logistics service quality. In turn, it will improve operational logistics service quality.

\section{Conclusion}

Collaboration is important in a supply chain. Previous studies show that companies that adopt supply chain collaboration have several benefits such as improving product quality, reducing costs, good risk management, reducing inventory levels, and improving customer service. This study proves that supply chain collaboration affects the quality of logistics services from 3PL relations. 3PLs that collaborate in exchanging information about the delivery schedule and selling process improved the quality of their relationship with SMEs in providing logistics services. Furthermore, good service and having knowledge of ordering products can affect the amount, accuracy, and condition of the order. A relational component in the ordering measured through personnel contact quality was proven to positively influence the operational elements. On the other hand, higher operational logistics service quality will significantly improve customer satisfaction. Delivering products on time as promised is the result of quality services from the operational logistics service provided by 3PL. Operational and relational performance relative to logistics services had a significant positive effect on customer satisfaction. Thus, 3PL has to pay attention to the quality of its logistics services to meet customer desires and exceed their expectations. Customer expectations that have been exceeded will lead to high performance of 3PL. This study only uses one 3PL with SMEs at its customer. Thus, in the future, this study needs to be continued by adding the number of $3 \mathrm{PL}$ as the subject being observed because it will increase the number of respondents as the study sample. 


\section{References}

[1] Cao M, Vonderembse MA, Zhang Q, Ragu-Nathan TS. Supply chain collaboration: Conceptualisation and instrument development. International Journal of Production Research 2010; 48(22):6613--6635. https://www.tandfonline.com/doi/abs/10.1080/ 00207540903349039

[2] Suwastika P. (2017, May). Peluang kolaborasi rantai pasok Indonesia [Indonesian supply chain collaboration opportunities, Online] from https://swa.co.id/swa/my-art icle/peluang-kolaborasi-rantai-pasok-indonesia. [Accessed on 19 September 2018]. [In Bahasa Indonesia]

[3] Leuschner R, Rogers DS, Charvet FF. A meta-analysis of supply chain integration and firm performance. Journal of Supply Chain Management 2013; 49(2):34-57. https: //onlinelibrary.wiley.com/doi/10.1111/jscm.12013.

[4] Chou S, Chen C, Kuo Y. Flexibility, collaboration and relationship quality in the logistics service quality: An empirical study. Asia Pacific Journal of Marketing and Logistics 2017; 30(3):555--570. https://www.researchgate.net/publication 1324765899_Flexibility_collaboration_and_relationship_quality_in_the_logistics_s ervice_industry_An_empirical_study

[5] Ha B, Park Y, Cho S. Suppliers' affective trust and trust in competency in buyers: Its effect on collaboration and logistics efficiency. International Journal of Operations \& Production Management 2011; 9(1):30--42. https://www.emerald.com/insight/conten t/doi/10.1108/01443571111098744/full/html

[6] Richey RG, Adams FG, Dalela V. Technology and flexibility: Enablers of collaboration and time-based logistics quality. Journal of Business Logistics 2012; 33(1):34--49. https://onlinelibrary.wiley.com/doi/abs/10.1111/j.0000-0000.2011.01036.x

[7] Stank TP, Keller SB, Daugherty PJ. Supply chain collaboration and logistical service performance. Journal of Business Logistics 2001; 22(1):29--48. https://onlinelibrary. wiley.com/doi/abs/10.1002/j.2158-1592.2001.tb00158.x

[8] Thai VV. Logistics service quality: Conceptual model and empirical evidence. International Journal of Logistic 2013; 16(2):114--131. https://www.tandfonline.com/do i/abs/10.1080/13675567.2013.804907

[9] Wagner BA, Fillis I, Johansson U. E-business and e-supply strategy in small and medium sized businesses (SMEs). Supply Chain Management: An International Journal 2003; 8(4):343--354. https://www.emerald.com/insight/content/doi/10.1108/ 13598540310490107/full/html 
[10] Wynarczyk P, Watson R. Firm growth and supply chain partnership: An empirical analysis of U.K. SME subcontractors, Small Business Economics 2005; 24(1):39--51. https://link.springer.com/article/10.1007/s11187-005-3095-0

[11] Rahman MNA. The effective implementation of global supply chain management in small to medium sized companies in Malaysia: An empirical study. International Journal of Management 2012; 29(3):274--287. https://www.semanticscholar.org/pa per/The-Effective-Implementation-of-Global-Supply-Chain-Rahman/42b717c1bf2a 8258a0504fe9a5cbbece154b9b9a

[12] Sharma SK, Gupta RD, Kumar A, Singh B. Supplier issue for lean implementation. International Journal of Engineering Science and Technology 2011; 3(5):3900--905. https://www.researchgate.net/publication/310753133_SUPPLIER_I SSUES_FOR_LEAN_IMPLEMENTATION

[13] Hamister JW. Supply chain management practices in small retailer. International Journal of Retail \& Distribution Management 2012; 40(6):427--450. https://www.em erald.com/insight/content/doi/10.1108/09590551211230250/full/html

[14] Zulkiffli SNA. The impact of supply chain operational capabilities on business performance of small and medium enterprises in Malaysia: A preliminary analysis. International Journal of Business and Management Science 2010; 3(2):233--258. https://www.researchgate.net/publication/286710494_The_impact_of_supply_cha in_operational_capabilities_on_business_performance_of_small_and_medium_e nterprises_in_Malaysia_A_Preliminary_analysis

[15] Mathuramaytha C. Supply chain collaboration -- What's an outcome?: A theoretical model. International Conference on Financial Management and Economics IPEDR 2011; 11:102--108. Retrieved from http://www.ipedr.com/vol11/20-R10023.pdf

[16] Wiengarten F, Humphreys P, Cao G, Fynes B, McKittrick A. Collaborative supply chain practices and performance: exploring the key role of information quality. Supply Chain Management: An International Journal 2010; 15(6):463-473. https://www.researchgate.net/publication/243974725_Collaborative_supply_c hain_practices_and_performance_Exploring_the_key_role_of_information_quality

[17] Simatupang TM, Sridharan R. An integrative framework for supply chain collaboration. The International Journal of Logistics Management 2005; 16(2):257--274. https: //www.emerald.com/insight/content/doi/10.1108/09574090510634548/full/html

[18] Jang HM, Marlow PB, Mitroussi K. The effect of logistics service quality on customer loyalty through relationship quality in the container shipping context. Transportation Journal 2013; 52(4):493--521. https://www.thefreelibrary.com/The+effect+of+logisti cs+service+quality+on+customer+loyalty+through...-a0352231546 
[19] Yang S, Liu J, Wang K, Miao Y. An uncertain QFD approach for the strategic management of logistics services. Mathematical Problems in Engineering 2016; 2016. https://www.hindawi.com/journals/mpe/2016/1486189/

[20] Davis-Sramek B, Mentzer JT, Stank TP. Creating consumer durable retailer customer loyalty through order fulfillment service operations. Journal of Operations Management 2008; 26(6):781--797. https://www.sciencedirect.com/science/article/ abs/pii/S0272696307000915

[21] Bouzaabia R, Bouzaabia O, Capatina A. Retail logistics service quality: A crosscultural survey on customer perceptions. International Journal of Retail \& Distribution Management 2013; 41(8):627--647. https://www.emerald.com/insight/content/doi/10. 1108/IJRDM-02-2012-0012/full/html

[22] Yuan X, Shi L, Li H.. Research on the relationship between the logistics service quality and customer loyalty in C2C e-commerce. WHICEB 2014 Proceedings 2014; 89. https://aisel.aisnet.org/whiceb2014/89/

[23] Otsetova A. Relationship between logistics service quality, customer satisfaction and loyalty in courier services industry. Management and Education 2017; XII(2):51--57. https://www.researchgate.net/publication/317039023_RELATIONSHIP_BETWEEN _LOGISTICS_SERVICE_QUALITY_CUSTOMER_SATISFACTION_AND_LOYALTY_I N_COURIER_SERVICES_INDUSTRY

[24] Lee J, Kim H, Ko YJ, Sagas M. The influence of service quality on satisfaction and intention: A gender segmentation strategy. Sport Management Review 2011; 14(1):54-63. https://www.sciencedirect.com/science/article/abs/pii/S1441352310000124

[25] Williams P, Ashill NJ, Naumann E, Jackson E. Relationship quality and satisfaction: Customer-perceived success factors for on-time projects. International Journal of Project Management 2015; 33(8):1836--1850. https://www.sciencedirect.com/scienc e/article/abs/pii/S0263786315001192 